\title{
Pilot study of a cell phone-based exercise persistence intervention post-rehabilitation for COPD
}

This article was published in the following Dove Press journal:

International Journal of COPD

5 August 2009

Number of times this article has been viewed

\section{Huong Q Nguyen' \\ Dawn P Gill' \\ Seth Wolpin' \\ Bonnie G Steele ${ }^{2}$ \\ Joshua $O$ Benditt'}

'University of Washington, Seattle, WA, USA; ${ }^{2}$ VA Puget Sound Health Care System, Seattle, WA, USA
Correspondence: Huong Q Nguyen University of Washington, Box 357266 , Seattle,WA 98199, USA

Tel + I 206543865 I

Fax + I $206543477 \mid$

Email HQN@u.washington.edu
Objective: To determine the feasibility and efficacy of a six-month, cell phone-based exercise persistence intervention for patients with chronic obstructive pulmonary disease (COPD) following pulmonary rehabilitation.

Methods: Participants who completed a two-week run-in were randomly assigned to either MOBILE-Coached $(n=9)$ or MOBILE-Self-Monitored $(n=8)$. All participants met with a nurse to develop an individualized exercise plan, were issued a pedometer and exercise booklet, and instructed to continue to log their daily exercise and symptoms. MOBILE-Coached also received weekly reinforcement text messages on their cell phones; reports of worsening symptoms were automatically flagged for follow-up. Usability and satisfaction were assessed. Participants completed incremental cycle and six minute walk (6MW) tests, wore an activity monitor for 14 days, and reported their health-related quality of life (HRQL) at baseline, three, and six months.

Results: The sample had a mean age of $68 \pm 11$ and forced expiratory volume in one second $\left(\mathrm{FEV}_{1}\right)$ of $40 \pm 18 \%$ predicted. Participants reported that logging their exercise and symptoms was easy and that keeping track of their exercise helped them remain active. There were no differences between groups over time in maximal workload, 6MW distance, or HRQL ( $p>0.05$ ); however, MOBILE-Self-Monitored increased total steps/day whereas MOBILE-Coached logged fewer steps over six months $(\mathrm{p}=0.04)$.

Conclusions: We showed that it is feasible to deliver a cell phone-based exercise persistence intervention to patients with COPD post-rehabilitation and that the addition of coaching appeared to be no better than self-monitoring. The latter finding needs to be interpreted with caution since this was a purely exploratory study.

Trial registration: ClinicalTrials.gov (NCT00373932).

Keywords: chronic obstructive pulmonary disease, physical activity, exercise persistence, pulmonary rehabilitation, cell phones

\section{Background}

Exercise is a well established intervention to improve physical functioning, symptoms, and quality of life in patients with chronic obstructive pulmonary disease (COPD). ${ }^{1}$ However, patients face multiple barriers to exercise persistence including episodic exacerbations of their illness, limited ongoing support, and low self-regulatory capacity. ${ }^{2-4}$ Supervised exercise training is a cornerstone of pulmonary rehabilitation (PR), a recommended multicomponent short-term intervention for patients with moderate to severe disease..$^{5}$ While notable improvements in functional outcomes are associated with rehabilitation, maintenance of independent exercise in the face of a progressive illness such as COPD is challenging. Numerous approaches of varying intensity and 
duration have been tested to help patients maintain functional gains achieved with PR including, extending the duration of rehabilitation, ${ }^{6}$ booster rehabilitation, ${ }^{7}$ or a combination of regular telephone follow-up contacts with clinic- or home-based supervised exercise sessions, ${ }^{8,9}$ support groups, ${ }^{2}$ or a pedometer-based home walking program. ${ }^{10}$ As a whole, these resource intensive models have yielded only modest long term effects compared to usual care. Despite these negative findings, the epidemiological evidence continues to argue for further refinement and testing of novel, targeted, cost-effective interventions to help patients at various stages of COPD maintain physically active lives. ${ }^{11}$

The pervasive integration of information and communication technologies in everyday life has ushered in a new age of anytime-anywhere information access and exchange. As an example, nearly $90 \%$ of the US adult population used a cell phone for their communication needs in 2008. ${ }^{12}$ Such widespread adoption of a simple innovation has opened up opportunities to cost-effectively scale up evidence-based interactive health promotion and disease management interventions. ${ }^{13}$ Cell phones are personal to the individual; they are always on and always connected thus enabling new types of health and social interactions otherwise not previously possible. Several recently published studies showed that cell phones can, in the short term, deliver effective behavior change interventions in young to middle age healthy adults ${ }^{14-17}$ as well as improve glucose and blood pressure control in patients with diabetes. ${ }^{18-20}$ Two studies, including our work on use of the Internet and cell phones to support dyspnea self-management, show that older adults with COPD are able and willing to use mobile devices for collaborative monitoring and communication to support self-care. ${ }^{21,22}$ Therefore, the purpose of this exploratory study was to determine the feasibility and efficacy of a first generation, cell phone-based exercise persistence intervention for patients with COPD following completion of PR.

\section{Methods}

\section{Study design}

We conducted a randomized, repeated measures $(0,3$, and 6 months) exploratory study to determine the feasibility and efficacy of a six-month cell phone-mediated cognitive-behavioral exercise persistence intervention, MOBILE (Mobilizing Support for Long-term Exercise), for patients with COPD. Patient graduates from four PR programs who successfully completed a two-week run-in period were randomized to receive either the MOBILE-Coached (MOBILE-C) or the active control, MOBILE-Self-Monitored
(MOBILE-SM) intervention. Since this was a feasibility study, we did not conduct an a priori power calculation; ${ }^{23}$ however, we had a target sample of 20 participants based on a realistic projection of the available PR graduate pool who would be willing to participate in the study over the limited recruitment time frame. The study was approved by the institutional review board at the University of Washington and was registered with ClinicalTrials.gov (NCT00373932).

\section{Recruitment}

Due to privacy regulations, participants were initially approached by PR coordinators for their interest in the research study. The PR coordinators provided the study with names and contact information of patients who expressed an interest in learning more about the study. The study RA either contacted the prospective participant via phone or arranged to meet him or her at the PR site to explain the study and obtain consent. The goal was to approach interested participants during the final 2-3 weeks of their PR program in order to allow a two-week run-in period; however, due to scheduling challenges, some participants did not start their run-in until they completed PR.

\section{Sample}

Inclusion criteria were: a) stable COPD; b) pulmonary function results show moderate to severe disease according to GOLD criteria (forced expiratory volume in one second $\left[\mathrm{FEV}_{1}\right]$ /forced vital capacity $[\mathrm{FVC}]<70 \%$ and $\mathrm{FEV}_{1}$ $<80 \%$ ); c) no plans to participate in a maintenance program; d) patients receiving supplemental oxygen were acceptable if their $\mathrm{O}_{2}$ saturation was maintained at $>88 \%$ on $<6 \mathrm{~L} / \mathrm{min}$ of nasal oxygen during the six minute walk (6MW) test; e) age $\geq 40$ years; f) ability to speak, read, and write English; and $\mathrm{g}$ ) permission from health provider. Exclusion criteria were: a) active symptomatic illness (eg, cancer, heart failure, ischemic heart disease, neuromuscular disease, psychiatric illness); b) unable (eg, severe arthritis) or unwilling to use the study issued cell phone; and c) reside outside of the wireless coverage area.

\section{Study procedures}

Participants completed a two-week run-in period in order to determine their ability to adhere to the exercise and symptom self-monitoring protocol. They were trained on entering data via the cell phone (Treo 650 or $700^{\mathrm{TM}}$, Palm Inc., Sunnyvale, CA, USA), asked to provide a return demonstration, and were given a step-by-step help booklet with screenshots 
of the cell phone displays. The Treo ${ }^{\mathrm{TM}}$ model was chosen because at the time of software development in 2005, it was the most affordable device with the largest screen size and touch screen interface, features that patients from another study felt were important. ${ }^{22}$ The study paid for the monthly data service plan. Participants who submitted at least $80 \%$ of exercise and symptom data during the run-in and chose to proceed with the study were scheduled for baseline testing (spirometry, incremental cycle, and 6MW tests, as well as questionnaires) and randomly allocated to MOBILE-C or MOBILE-SM. A biostatistician who was not involved in the day-to-day study operations generated the randomization sequence and placed the randomization in separate sealed opaque envelopes. The randomization scheme was stratified by gender to ensure balanced allocation. The interventionist was not blind to group assignment; however, the outcome assessments were performed by a research assistant who was blinded to this information. All participants met individually with the study interventionist (HQN) for a 30 to 45 -minute baseline consultation as described below. Participants returned for testing three and six months later.

\section{MOBILE interventions}

Participants from both treatment groups met with HQN at baseline to collaboratively design a safe, simple, and effective independent exercise program that they were likely to sustain over time. The exercise program was individualized according to participants' performance on the exercise tests, dyspnea at end of exercise, access to community-based exercise facilities, and preferred exercise mode. They were encouraged to accumulate up to a total of 150 minutes of moderate-intensity endurance exercise per week (3-5 sessions per week) per national physical activity guidelines and to continue with upper and lower body resistance exercises initiated during PR. The nurse also discussed signs and symptoms participants typically experienced with the onset of a COPD exacerbation, strategies for self-care, and how to adjust exercise as needed during these episodes. Participants were given a copy of a generic exacerbation action plan with their specific signs and symptoms listed and were encouraged to discuss and modify the action plan with their health provider. They were provided a booklet with exercise tips, local resources, and pictures of stretching and strengthening exercise as well as an Omron HJ-112 digital pedometer (Omron Healthcare, Bannockburn, IL, USA); pedometers are simple self-monitoring tools that provide immediate and objective feedback and, in turn, may provide behavioral reinforcement. ${ }^{24}$ Both programs were grounded in behavior change theories and operationalized through the behavioral components of self-monitoring (MOBILE-SM) and motivational feedback and assistance with problem solving to develop self-regulatory capacity for exercise persistence (MOBILE-C). ${ }^{25-27}$

\section{MOBILE-Coached (MOBILE-C)}

There were two components to MOBILE-C: collaborative monitoring of symptoms and exercise and ongoing reinforcement feedback.

\section{Collaborative monitoring of symptoms and exercise}

Participants submitted daily information about their symptoms and exercise. An audio alarm was set on the cell phone calendar tool to remind participants to complete their entries at a time that was acceptable to them. The data were transmitted in real-time to a central server and the nurse was able to review these data for each participant or in aggregate form.

Participants used Likert scales to rate their overall health (excellent to poor) and respiratory symptoms (difficulty breathing [0: none to 4 : severe], cough [0: none to 4 : almost constant], and trouble with sputum [0: none to 4: severe]). Automatic alerts were sent to the nurse's cell phone if participants responded having "marked" symptoms for two consecutive days. The nurse followed up via text messaging or telephone as necessary. Participants were encouraged to contact their health provider regarding the increasing symptoms, to follow their treatment plan, and to continue to $\log$ their data during the exacerbation episode.

Participants entered the following information about their exercise: mode (walking, biking, other endurance exercises, and upper and lower body strengthening exercises), duration (minutes and/or total daily steps), and worst dyspnea during the endurance exercise using a 0-10 modified Borg scale. If participants indicated they were not able to exercise, they were asked to select reasons from a list of common barriers (COPD flare-up, difficulty breathing, too tired, not motivated, depressed, too busy, sick, bad weather, bored with exercise, family responsibilities, on vacation, and pain/discomfort). Once the data were submitted and sent to the central server, participants received an instant text feedback summarizing the exercises they completed for that week.

\section{Reinforcement feedback}

Ongoing reinforcement feedback was provided via weekly short text messages to the participant's cell phone, by the nurse, based on submitted exercise and symptom information, 
eg, "You've got it, getting more 'bang' for your buck is what the conditioning is all about. What a great feeling it must be to know you can do more!", "I saw that you were quite busy this week and not able to get much walking as usual. Perhaps you could do three 10-minute walks until things slow down?" Participants confirmed receipt of these messages by replying with short text responses or less frequently, with several follow up text messages. Examples of participant messages include: "I think I mentioned I do more exercise when nagged so do nag!!”, “This program helps me a lot. I am able to stay focused. Again thanks", and "Thank you for that, atta boy!"

Because of the small QWERTY keyboard and 160 character restriction for each message, participants were telephoned for situations where more extensive interactions was appropriate, eg, coaching on problem solving strategies to overcome reported barriers to exercise, assessing whether participants were experiencing an exacerbation and encouraging follow up with their health provider, or assistance with adjustments to exercise goals in response to changes in health status. Template text messages were also pre-programmed on the cell phone in an attempt to make it easier for participants to communicate via text messaging, eg, "I need to talk to you. Can you call me at home?", "I think I'm having a COPD flare-up. I've called my doc", "Will increase the duration of my walks this week by x", "Just wanted to let you know I'm planning to take a vacation from exercise for a week".

\section{MOBILE-Self-Monitored (MOBILE-SM)}

Participants continued to use the cell phone to enter information about their symptoms and exercise on a daily basis and were encouraged to call the research office if they had questions about their exercise or COPD over the course of the study. They were informed that self-monitoring helped others stay committed to their exercise program. A standard text message was sent to participants each week to thank and encourage them to continue to submit their data, eg, "Thank you for your continued efforts with the entries.", "Thank you for your regular entries. Your effort is greatly appreciated." Aside from the daily automatic calendar reminder to log their information, MOBILE-SM participants did not receive any other prompting or personalized feedback; the symptom alert was also disabled.

\section{Measurements}

Technical issues and usability

Participants were asked several open-ended questions by telephone, regarding technical difficulties within the first week of the run-in period. Technical difficulties such as missing or compromised data, battery failure, damage, malfunctioning or lost cell phones were tracked. Usability and acceptability were assessed at three and six months with a survey using a Likert type scale and a semi-structured exit interview at six months.

\section{Beliefs and attitudes towards exercise and self-care}

At baseline, participants completed one-item questions assessing their: 1) satisfaction with rehabilitation's effects on their overall health, "Given the effort you've put into your pulmonary rehabilitation program, how satisfied are you with your overall health?" (0: not at all satisfied to 5: very satisfied); 2) expectations that persisting with exercise would help maintain their health, "If you were to continue to exercise on your own after the rehab program, how much do you expect that the exercise will help with your overall health?" (0: not at helpful to 5: very helpful); and 3) perceived importance, motivation, and confidence to continue their exercise, "How [important is it to you-, motivated are you-, confident are you-] to continue to exercise on your own as a way to manage your breathing?" (0: not at all to 10: totally). They also completed two validated questionnaires that measured the degree of autonomous self-regulation for exercise (15-items, Self-Regulatory Questionnaire-Exercise $[\mathrm{SRQ}-\mathrm{E}])^{28,29}$ and activation for self-care (13-items, Patient Activation Measure [PAM]). ${ }^{30,31}$ Self-efficacy for overcoming barriers to exercise was measured using a 15-item Exercise Barriers Efficacy Scale; ${ }^{32,33}$ this scale was re-administered at three and six months.

\section{Support for exercise}

Support for exercise was measured with a 13-item Social Support and Exercise Survey. ${ }^{34}$ This instrument has been used extensively in both healthy and clinical populations to assess enacted support from family and friends specific to exercise (eg, exercised with me, encouraged me to exercise). ${ }^{35}$ Participants were also asked to rate their overall perceived support for exercise from people closest to them using a 1 to 5 point Likert scale.

\section{Exercise performance}

Exercise performance was assessed using the six-minute walk (6MW) and incremental cycle ergometer tests. Participants performed two 6MW tests according to ATS guidelines and the longer of the two tests was used for analysis. ${ }^{36}$ The incremental cycle ergometer test protocol was similar to that used in the National Emphysema Treatment Trial. ${ }^{37}$ Duration and peak workload measured in watts was recorded. 
Cardiorespiratory status was not measured since previous studies showed minimal to no changes in physiological parameters with moderate-intensity, independent exercise programs. $^{38,39}$

\section{Free-Living Ambulatory Physical Activity}

Free-living ambulatory physical activity was measured using a pager-sized, lightweight, Stepwatch ${ }^{\circledR} 3$ Activity Monitor (SAM; OrthoCare Innovations, Washington DC, USA) fastened above the right ankle. The SAM is a dual-axis accelerometer linked to a microprocessor sensor that directly and continuously records gait cycles (strides) based on acceleration, position, and timing information. Stride counts are doubled to represent steps. The SAM has been validated for use in healthy and chronically ill older adults in laboratory and community settings and has an accuracy of $98 \%-99 \%{ }^{40,41}$ Participants wore the SAM during waking hours for 14 days at baseline, three, and six months. The SAM was programmed to record in one-minute epochs; a valid day was defined as having 10 or more hours (600 min) of monitor wear. The device software was used to calculate total step counts, percent of time during waking hours without any steps (inactive), percent active time at moderate (31-80 steps/min) and high intensity activity ( $>80$ steps $/ \mathrm{min}$ ), and peak performance (average steps/min of the best 30 minutes of the day).

\section{Health related quality of life (HRQL)}

Health-related quality of life (HRQL) was measured with two validated generic and disease-specific instruments, the Medical Outcomes Study Short-Form 36 (MOS-SF36) ${ }^{42}$ and St. George's Respiratory Questionnaire (SGRQ). ${ }^{43,44}$ The SF-36 produces two composite scales of physical and mental functioning with higher scores indicating better HRQL. The 76-item SGRQ measured the three domains of respiratory symptoms, activities, and impact, providing a total SGRQ score. Lower scores indicate better HRQL.

\section{Statistical analysis}

Independent Student's $t$-tests or chi-squared tests were used to compare baseline characteristics between groups. General linear mixed models, a well-established class of linear models particularly suited for longitudinal repeated measures data that does not exclude individuals with missing data, were used to estimate the effect of treatment, adjusting for individual variation in the outcomes of exercise performance, physical activity, and HRQL. Significance was determined using Wald tests $(\mathrm{p}<0.05)$. Since this was an exploratory study and not designed to be adequately powered for detecting differences between groups, we did not adjust the alpha levels for testing multiple outcome variables.

\section{Results}

\section{Sample flow and baseline characteristics}

A total of 43 patients with COPD were referred to the research study from October 2006 to April 2008. Nine patients were deemed ineligible for the following reasons: not completing PR due to death or other reasons, other pulmonary diagnoses, non-English speaking, major surgery, medical complications immediately post-PR, or severe hearing impairment. Other patients expressed no interest in the study $(\mathrm{n}=8)$, were too busy $(\mathrm{n}=2)$, not reachable $(n=6)$, or withdrew after the first run-in week $(\mathrm{n}=1)$, leaving a total of 17 participants who completed the two-week run-in for randomization to MOBILE-SM $(\mathrm{n}=9)$ or MOBILE-C $(\mathrm{n}=8)$ (Figure 1).

The sample characteristics are described in Table 1. Age and disease severity were not comparable between the two groups, suggesting that randomization in this small sample was only marginally successful. Both groups were similarly satisfied with the positive effects of PR on their overall health and had high expectations that continued participation in exercise would maintain their health. Motivation and confidence to persist with exercise tended to be lower in MOBILE-SM. Overall activation for self-care and self-regulation for exercise were relatively high for both groups. While enacted support for exercise from family and friends were similarly low across all participants, the MOBILE-C group reported slightly higher overall perceived support for their exercise.

\section{Process and mediating measures}

\section{Technical issues and usability}

There were three separate instances where the cell phone fell out of the wireless network and participants were instructed via telephone to perform either a soft or hard reset with removal of the batteries without difficulties. Two devices had to be exchanged due to persistent unreliable connections to the network. Since $90 \%$ of the participants already had a cell phone for personal use, the study-issued cell phone was seldom carried by the participant. Forgetting to charge the device and not getting the audio reminder were primary reasons participants cited for forgetting to log their daily information. Participants in both groups found that it was easy to submit their data and that the time (approximately 1-2 min) to complete the task was acceptable (Table 2). 


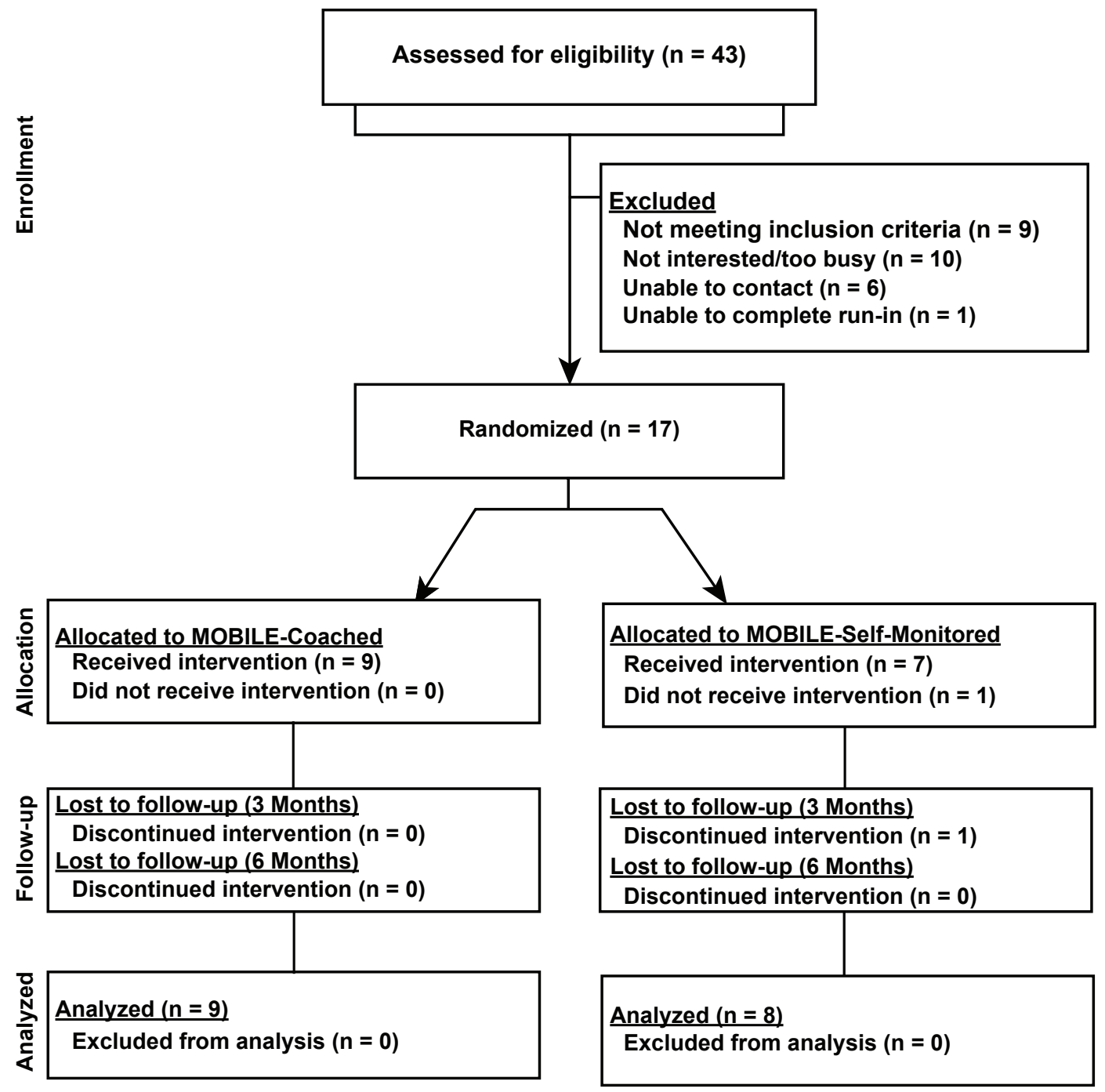

Figure I Sample flow.

Abbreviation: MOBILE, Mobilizing Support for Long-term Exercise.

They agreed that keeping track of their exercise helped them stay committed. Text messaging was not perceived favorably by all MOBILE-C participants. Three participants who found it difficult to navigate to the texting tool and use the small keyboard expressed a strong preference for communication via the telephone. One participant who text messaged the nurse most frequently stated that she developed her texting skills because she wanted to communicate with her grandchildren and actually came to appreciate this form of communication.

\section{Exercise and symptom entries}

Participants submitted a total of 2338 exercise and 2400 symptom entries (Table 2); there was a wide range in the number of entries across both groups. Overall, MOBILE-C participants were more "adherent" in submitting their exercise and symptom data compared to MOBILE-SM, $87 \%$ vs $66 \%$ over six months.

\section{Validation of self-reported exercise}

Weighted correlation between self-report of exercise ( $n=448$ days) and total SAM step counts for the particular monitored day was modest $(r=0.36, p=0.15)$ but trended in the right direction. The percentage of time engaged in moderate to high intensity physical activity was greater on days that participants reported exercising compared to days when they did not exercise.

\section{Barriers to exercise and adverse events}

Participants in both groups made a total of 811 entries reporting their barriers to exercise. The most frequent exercise barriers were being too busy $(n=300)$ or having family responsibilities 
Table I Baseline sample characteristics

\begin{tabular}{|c|c|c|}
\hline & MOBILE-SM $(n=8)$ & MOBILE-C $(n=9)$ \\
\hline \multicolumn{3}{|l|}{ Demographics } \\
\hline Age & $64 \pm 12$ & $72 \pm 9$ \\
\hline Female (\%) & $5(63 \%)$ & $6(67 \%)$ \\
\hline College educated or higher & $7(88 \%)$ & $6(67 \%)$ \\
\hline \multicolumn{3}{|l|}{ Race/ethnicity } \\
\hline Caucasian & $6(75 \%)$ & $8(89 \%)$ \\
\hline African-American & $2(25 \%)$ & I (II\%) \\
\hline Married/partnered & $3(38 \%)$ & $2(22 \%)$ \\
\hline Computer user & $8(100 \%)$ & $7(78 \%)$ \\
\hline \multicolumn{3}{|l|}{ Clinical status } \\
\hline BMI & $25.0 \pm 7.8$ & $26.3 \pm 5.5$ \\
\hline $\mathrm{FEV}_{1} / \mathrm{FVC}$ & $0.39 \pm 0.12$ & $0.48 \pm 0.10$ \\
\hline $\mathrm{FEV}, \%$ predicted & $34.4 \pm 15$ & $46.7 \pm 18.7$ \\
\hline \multicolumn{3}{|l|}{ GOLD } \\
\hline Stage 2 & $2(25 \%)$ & $3(33 \%)$ \\
\hline Stages 3 and 4 & $6(75 \%)$ & $6(67 \%)$ \\
\hline BODE Index $(\downarrow 0-10)$ & $3.7 \pm 1.3$ & $3.0 \pm 2.4$ \\
\hline Comorbidities $(\geq I)$ & $5(63 \%)$ & $6(67 \%)$ \\
\hline Supplemental oxygen & $5(63 \%)$ & $5(56 \%)$ \\
\hline \multicolumn{3}{|l|}{ Beliefs and attitudes towards exercise and self-care } \\
\hline Satisfaction with rehab on overall health $(0-5 \uparrow)$ & $3.0 \pm 1.8$ & $3.0 \pm 1.2$ \\
\hline $\begin{array}{l}\text { Expectations that continued exercise will help } \\
\text { maintain overall health }(0-5 \uparrow)\end{array}$ & $4.4 \pm 0.7$ & $4.3 \pm 0.5$ \\
\hline Importance of continuing exercise $(0-10 \uparrow)$ & $8.9 \pm 1.0$ & $9.2 \pm 2.0$ \\
\hline Motivation to continue exercise $(0-10 \uparrow)$ & $7.8 \pm 1.3$ & $8.7 \pm 1.9$ \\
\hline Confidence to continue exercise $(0-10 \uparrow)$ & $7.1 \pm 2.8$ & $8.7 \pm 1.3$ \\
\hline 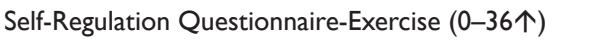 & $20.1 \pm 4.5$ & $21.0 \pm 8.4$ \\
\hline Patient Activation Measure $(\downarrow / 3-52)$ & $20.5 \pm 4.4$ & $20.9 \pm 4.7$ \\
\hline \multicolumn{3}{|l|}{ Resources and support for exercise } \\
\hline Home exercise equipment (cycle or treadmill) & $2(25 \%)$ & $3(33 \%)$ \\
\hline Has access to a local exercise facility & $3(38 \%)$ & $4(44 \%)$ \\
\hline Enacted support for exercise from family (13-65个) & $19.7 \pm 5.8$ & $22.6 \pm 4.3$ \\
\hline Enacted support for exercise from friends (13-65个) & $20.1 \pm 4.5$ & $21.0 \pm 8.4$ \\
\hline Overall perceived support for exercise $(I-5 \uparrow)$ & $2.9 \pm 1.5$ & $4.0 \pm 1.1$ \\
\hline
\end{tabular}

Notes: Mean \pm SD or count (percentage); $\uparrow$ or $\downarrow$ indicate better ratings.

Abbreviations: BMI, body mass index; FEV , forced expiratory volume in one second; FVC, forced vital capacity; GOLD, Global Initiative for Chronic Obstructive Lung Disease; MOBILE, Mobilizing Support for Long-term Exercise; MOBILE-C, MOBILE-Coached; MOBILE-SM, MOBILE-Self-Monitored; SD, standard deviation.

$(\mathrm{n}=119)$, followed by being too tired $(\mathrm{n}=106)$. Four participants experienced a COPD exacerbation that required treatment with antibiotics or oral prednisone; two had a fall unrelated to exercise, that required surgery or immobilization; and one participant was listed for lung transplant and received her transplant three months into the study.

\section{Self-efficacy for overcoming barriers to exercise}

Self-efficacy was lower for the MOBILE-SM group compared to MOBILE-C at baseline ( $4.8 \pm 1.6$ vs. $7.1 \pm 0.6)$ but increased at six months $(6.0 \pm 0.9)$ whereas the MOBILE-C group showed a decline $(6.2 \pm 0.6)$ (group $\times$ time interaction, $\mathrm{p}=0.08)$

\section{Exploratory analysis of outcomes}

\section{Exercise performance}

The MOBILE-SM group showed modest increases whereas the MOBILE-C group had declines in maximal workload on the incremental cycle ergometer and 6MW 
Table 2 Usability of study-issued cell phones and daily log entries

\begin{tabular}{|c|c|c|}
\hline & MOBILE-SM $(n=8)$ & MOBILE-C $(n=9)$ \\
\hline \multicolumn{3}{|l|}{ Usability } \\
\hline Easy to submit exercise data & $1.7 \pm 0.5$ & $1.4 \pm 0.5$ \\
\hline Easy to submit symptom data & $1.7 \pm 0.5$ & $1.5 \pm 0.5$ \\
\hline Time needed to submit data was just right & $1.9 \pm 0.9$ & $1.6 \pm 0.5$ \\
\hline Keeping track of exercise kept me going & $1.6 \pm 0.5$ & $1.4 \pm 0.5$ \\
\hline Easy to read text messages from nurse & N/A & $1.9 \pm 0.8$ \\
\hline Easy to send text messages to nurse & $\mathrm{N} / \mathrm{A}$ & $1.9 \pm 0.8$ \\
\hline Text messages from nurse helped me stick with my exercise & N/A & $\mathrm{I} .8 \pm 0.7$ \\
\hline Helpful that I could send text message to the nurse anytime & N/A & $1.9 \pm 0.6$ \\
\hline Recommend MOBILE program to other rehab graduates & $1.2 \pm 0.4$ & $1.0 \pm 0$ \\
\hline \multicolumn{3}{|l|}{ Daily log entries } \\
\hline $\begin{array}{l}\text { Total exercise entries } \\
\text { (mean entries per participant; range) }\end{array}$ & $\begin{array}{l}947 \\
(118 ; 28-176)\end{array}$ & $\begin{array}{l}1390 \\
(154 ; 79-180)\end{array}$ \\
\hline $\begin{array}{l}\text { Total symptom entries } \\
\text { (mean entries per participant; range) }\end{array}$ & $\begin{array}{l}996 \\
(125 ; 28-176)\end{array}$ & $\begin{array}{l}1404 \\
(156 ; 85-180)\end{array}$ \\
\hline
\end{tabular}

Notes: Mean \pm SD; Usability response scale: I: strongly agree, 2: agree; 3: disagree; 4: strongly disagree; all between group comparisons, $\mathrm{p}>0.05$.

Abbreviations: MOBILE, Mobilizing Support for Long-term Exercise; MOBILE-C, MOBILE-Coached; MOBILE-SM, MOBILE-Self-Monitored.

distance; these differences were not statistically significant (see Table 3; $p=0.29$ and 0.12 ).

\section{Free-living ambulatory physical activity}

Trends in the four physical activity parameters (total steps/day, percentage time being inactive, percentage time active at moderate or high intensity, and peak performance) also tracked changes observed in the laboratory exercise performance tests (Table 3); MOBILE-SM participants increased their physical activity over six months whereas MOBILE-C showed a decline. There was a significant interaction of treatment group and time in three of the four physical activity outcomes. MOBILE-SM participants accrued more steps per day $(\mathrm{p}=0.04)$, presumably through greater participation in moderate to high intensity exercise $(p=0.003)$, and had higher peak performance $(p=0.002)$. The proportion of waking time that all participants were inactive did not significantly change over time.

Health-related quality of life (HRQL)

There were no between group differences for the SGRQ total score ( $p=0.15)$ or the SF-36 physical and mental composite scales $(p=0.51$ and $p=0.38)($ Table 4$)$.

\section{Qualitative interviews}

Irrespective of the treatment groups, two major themes emerged from the semi-structured exit interviews: 1) Participants' desire to stay accountable; and 2) Participants' motivation to establish an independent exercise routine after PR.

"I wanted to stay accountable since I knew that if I commit to something, I'd be more likely to do it. The cell phone kept me honest, I knew I had to fess up if I didn't do my exercises-that kind of motivation really helps. The summary feedback of how much I've done for the week also helps me know if I'm slacking off and how much I still need to do." "The study has made me more motivated than before to keep exercising even though I don't like it. I know it makes me feel good so I have to keep going. Having to report what I do and getting feedback on how I'm doing makes me pay attention to what I'm doing"

"Participating in this program for an extra six months after rehab was really helpful because it gave me time to establish a routine for exercise. I now do the exercises for myself because I know it makes me feel good."

\section{Intervention time and costs}

All participants had an initial 30-45 minute face-to-face meeting with a nurse $(\sim 25$, assuming an annual salary of $\$ 80 \mathrm{~K})$. The nurse spent up to five minutes per MOBILE-C participant per week reviewing submitted data and providing text reinforcement ( 5 mins $\times 24$ weeks; two hours, $\sim \$ 80$ ). Most MOBILE-C participants received at least one or two 10-minute telephone calls over the course of six months $(\sim \$ 15)$. Approximately 1-2 minutes were spent on text messages per week to MOBILE-SM 
Table 3 Changes in exercise performance and physical activity at three and six months post-pulmonary rehabilitation

\begin{tabular}{|c|c|c|c|}
\hline & MOBILE-SM $(n=8)$ & MOBILE-C $(n=9)$ & Group $\times$ Time $p$ value \\
\hline \multicolumn{4}{|c|}{ Incremental cycle test (watts) } \\
\hline Baseline & $47.9 \pm 8.9$ & $54.4 \pm 7.9$ & 0.29 \\
\hline 6 months & $49.2 \pm 9.6$ & $48.9 \pm 7.9$ & \\
\hline \multicolumn{4}{|c|}{ Six minute walk (feet) } \\
\hline Baseline & $1200 \pm 133$ & $1240 \pm 125$ & 0.12 \\
\hline 3 months & $1222 \pm 134$ & $1206 \pm 127$ & \\
\hline 6 months & $1268 \pm 136$ & $1194 \pm 125$ & \\
\hline \multicolumn{4}{|c|}{ Total steps/day } \\
\hline Baseline & $5229 \pm 1068$ & $6692 \pm 1007$ & 0.04 \\
\hline 3 months & $4452 \pm 1082$ & $5879 \pm 1016$ & \\
\hline 6 months & $5838 \pm 1096$ & $5675 \pm 1007$ & \\
\hline \multicolumn{4}{|c|}{ \% Time inactive } \\
\hline Baseline & $68.9 \pm 4.3$ & $67.7 \pm 4.1$ & 0.71 \\
\hline 3 months & $73.8 \pm 4.3$ & $70.0 \pm 4.1$ & \\
\hline 6 months & $69.3 \pm 4.4$ & $69.5 \pm 4.1$ & \\
\hline \multicolumn{4}{|c|}{$\begin{array}{l}\text { \% Active time at moderate-high } \\
\text { activity }\end{array}$} \\
\hline Baseline & $19.1 \pm 2.7$ & $27.1 \pm 2.6$ & 0.003 \\
\hline 3 months & $18.6 \pm 2.8$ & $24.2 \pm 2.6$ & \\
\hline 6 months & $23.5 \pm 2.9$ & $23.6 \pm 2.6$ & \\
\hline \multicolumn{4}{|c|}{ Peak performance } \\
\hline Baseline & $61.2 \pm 5.4$ & $68.4 \pm 5.0$ & 0.002 \\
\hline 3 months & $59.0 \pm 5.6$ & $59.0 \pm 5.2$ & \\
\hline 6 months & $68.2 \pm 5.8$ & $56.6 \pm 5.0$ & \\
\hline
\end{tabular}

Notes: *Adjusted mean \pm SE; \% time inactive: time during waking hours without any steps; moderate activity ( $3 \mathrm{I}-80 \mathrm{steps} / \mathrm{min})$; high activity ( $>80$ steps/min); peak performance: average steps/minute of the best 30 minutes of the day.

Abbreviations: MOBILE, Mobilizing Support for Long-term Exercise; MOBILE-C, MOBILE-Coached; MOBILE-SM, MOBILE-Self-Monitored; SE, standard error.

participants $(1 \mathrm{~min} \times 24$ weeks; $\sim \$ 20)$. We purchased a total of 10 Treo $650 / 700^{\mathrm{TM}}$ cell phones at $\$ 300 /$ device; each phone was used by at least two participants; wireless data and text message service was $\$ 35 /$ month per device. Software development cost was only $\$ 3,000$ (30\% FTE for an experienced programmer for two months) since we were able to modify an existing platform. The approximate total intervention costs were $\$ 655$ and $\$ 580$ for a MOBILE-C and MOBILE-SM participant, respectively. Nearly $90 \%$ of the intervention cost was due to the software, hardware, and wireless service; however, per person costs are expected to be far lower in the future since patients are likely to use their own cell phones, pooled data service negotiations are now possible with wireless providers, and incremental costs for additional users will be negligible.

\section{Discussion}

We showed that it is feasible to deliver a cell phone-based exercise persistence intervention to patients with COPD and that the addition of coaching by a nurse (MOBILE-C) did not appear to be better than ongoing self-monitoring(MOBILE-SM) for maintenance of functional outcomes six-months post-PR. In fact, MOBILE-SM showed significant improvements in physical activity over time compared to declines in MOBILE-C. To our knowledge, this is the first study to test the use of a first generation, cell phone-based intervention to encourage exercise persistence for patients with COPD after PR.

The primary assumption of this study was that exercise persistence is critical to maintenance of gains in or at least attenuation of expected decline in physical functioning for a chronic, progressive illness such as COPD. Shortterm PR remains the recommended standard of care for patients with moderate to severe COPD. Unfortunately, the limited nature of PR as currently structured and reimbursed provides insufficient support for ongoing self-regulatory demands associated with long-term behavior change and efforts at developing durable exercise habits. The MOBILE 
Table 4 Changes in health-related quality of life (HRQL) at three and six months post-pulmonary rehabilitation

\begin{tabular}{|c|c|c|c|}
\hline Questionnaire & MOBILE-SM $(n=8)$ & MOBILE-C $(n=9)$ & Group $\times$ Time $p$ value \\
\hline \multicolumn{4}{|c|}{$\begin{array}{l}\text { St George's respiratory total score } \\
\text { (SGRQ, } \downarrow 0-100)\end{array}$} \\
\hline Baseline & $50.7 \pm 5.0$ & $38.3 \pm 4.7$ & 0.15 \\
\hline 3 months & $54.4 \pm 5.0$ & $39.0 \pm 4.7$ & \\
\hline 6 months & $45.2 \pm 5.2$ & $4 I .7 \pm 4.7$ & \\
\hline \multicolumn{4}{|c|}{$\begin{array}{l}\text { SF-36 Composite physical functioning } \\
(0-100 \uparrow)\end{array}$} \\
\hline Baseline & $31.4 \pm 2.4$ & $32.8 \pm 2.3$ & 0.51 \\
\hline 3 months & $27.5 \pm 2.4$ & $32.9 \pm 2.3$ & \\
\hline 6 months & $30.3 \pm 2.5$ & $33.8 \pm 2.3$ & \\
\hline \multicolumn{4}{|c|}{$\begin{array}{l}\text { SF-36 Composite mental functioning } \\
(0-100 \uparrow)\end{array}$} \\
\hline Baseline & $54.2 \pm 4.1$ & $50.6 \pm 3.8$ & 0.38 \\
\hline 3 months & $48.4 \pm 4.1$ & $48.5 \pm 3.8$ & \\
\hline 6 months & $55.2 \pm 4.2$ & $46.9 \pm 3.8$ & \\
\hline
\end{tabular}

Notes: *Adjusted mean $\pm \mathrm{SE}$.

Abbreviations: MOBILE, Mobilizing Support for Long-term Exercise; MOBILE-C, MOBILE-Coached; MOBILE-SM, MOBILE-Self-Monitored; SE, standard error.

interventions were designed as two competing models to extend the effects of PR by using what has now become a pervasive personal communication tool, the cell phone. MOBILE-SM was modeled as a low intensity, affordable active control intervention (individualized exercise plan, pedometer, and daily self-monitoring of symptoms and exercise) that could easily be scaled up. MOBILE-C included the same elements in addition to immediate feedback of exercise progress and more real-time, ongoing reinforcement and problem-solving assistance from a nurse, mirroring the intensity of previous exercise maintenance approaches..$^{8,10}$

Based on behavior change theory and findings from previous studies, we hypothesized that MOBILE-C participants who received more intensive follow up and support would show a trend in better maintenance of functional outcomes; however, this was not the case. The statistically significant differences between groups in physical activity may have been spurious since this study was not sufficiently powered to detect group differences. Nonetheless, the consistent trend in the activity data suggests two possible explanations for the unexpected finding that MOBILE-SM was more effective compared to MOBILE-C. The differences in baseline characteristics, greater number of adverse events in MOBILE-C (two falls and three COPD exacerbations), and relatively small sample size may have created a situation where outliers adversely influenced the mean estimates. Also, MOBILE-C participants scored higher on all measured outcomes at baseline, thus regression to the mean offers another possible explanation.

Alternatively, the MOBILE-SM active control intervention was rather robust. Use of pedometers alone has been shown to increase total step counts on non-PR days for patients participating in $\mathrm{PR} .{ }^{45}$ Moreover, the act of recording pedometer steps which presumably increases the relevance and processing of this information resulted in higher step counts than if participants wore the pedometers without recording their steps as found in a recent study. ${ }^{46}$ Since we did not measure ambulatory physical activity pre-PR, we could not determine if levels at six months for both groups were still above baseline.

Step counts vary substantially depending on disease severity. A recent cross-sectional study showed that patients with GOLD Stage IV disease accrued on average $<3,000$ steps/day compared to $\sim 8,000$ steps/day for GOLD I-II patients. ${ }^{47,48}$ deBlock and colleagues ${ }^{45}$ reported that patients with moderate to very severe COPD averaged 2,200 steps/day pre-PR and increased their step counts by $+1,200$ steps/day post-PR. In another study of a 12-week pedometer-based cognitive behavioral intervention in GOLD Stage I-III COPD patients, Hospes and colleagues ${ }^{49}$ found a difference of 2,152 steps/day between intervention (+785 steps/day) and control patients $(-1,367$ steps/day). Participants in this study registered on average 5,700 steps/day six months after PR which translates to approximately 2.5 miles of ambulatory activity per day. 
While lower than what is typically recommended for healthy adults (10,000 steps/day), this level of activity is likely well above pre-PR activity levels though this will need to be measured in future studies. A recent study of a six-month PR program found that significant increases in walking time above baseline (10 $\mathrm{min} /$ day; $+20 \%$ ) was observed only after six months of training, not earlier at three months. This increase was actually not due to the exchange of shorter periods of walking for longer periods; $83 \%$ of patients substituted lying time for more short bursts of walking time. ${ }^{50}$ Additional work will need to examine whether extended supervised training or a program like MOBILE or a combination thereof is more cost-effective in helping patients with COPD sustain a physically active lifestyle.

The automated audio reminders, originally intended to prompt participants to submit information about their daily symptoms and exercise actually served as a potent prompt for exercise as evidenced by the qualitative findings. Participants in both groups often alluded to the sense of accountability as a key factor that sustained their commitment to persist with exercise, a common observation of other studies as well. ${ }^{51}$ Similarly, the act of reporting their barriers to exercise in real-time may have activated certain internal cognitive or motivational processes and should be explored further as a possibly effective strategy to motivate certain subgroups of patients. In contrast to a previous study that identified chest infections (COPD exacerbations) as the most common barrier to exercise based on retrospective self report, ${ }^{2}$ our study found that being "too busy" was the number one reason participants cited for not exercising. This difference in findings may be due to disease severity and seasonality; however, the stark differences between retrospective recall and real-time reporting merits additional study to truly understand the barriers to exercise in this population. Finally, the usability data and qualitative feedback suggested that text messaging had only modest utility for one third of the MOBILE-C participants; thus, the relative advantage of instant personalized communication with the nurse was not fully realized.

The small sample size and self-selected nature of the sample represent important limitations of this exploratory study. Participants who are referred by PR coordinators, are able to complete PR, and are able to complete the run-in period are already a highly selected, motivated group; it was however encouraging that we excluded prospective participants for reasons other than successful completion of the run-in. Recruitment of participants from four PR programs could have introduced heterogeneity in baseline characteristics; however, there is also within-center variability in response to PR. The quality of life instruments used in this study may not been responsive to measuring change. We were not able to maximize the full potential of the cell phone as an always on, connected device for real-time support since most participants did not carry the device on them due to the bulky form factor but also, because $90 \%$ of the participants already had their own cell phone. An important technical consideration for future studies of cell phone-based health interventions is the need to develop platform-independent applications that can easily load on devices that patients own. Aside from the costs of purchasing devices that quickly become obsolete, patients are far more likely to use health applications that reside on their own personal device. Finally, the most optimal model of integrated care combined with active elements of PR remains unclear and continues to be an ongoing area of research; thus the approach we took of "back loading" a technology mediated intervention post-PR is only one of many possibilities for integrating communication tools to support patients.

\section{Conclusions}

We found that patients with COPD were willing and able participate in a first generation cell phone-based exercise persistence intervention despite several technological challenges. To our surprise, the self-monitored group showed greater improvements in free-living physical activity compared to the coached group that received personalized reinforcement and support over six months but this finding should be interpreted with caution. Additional research is warranted on the use of mobile devices and other interactive communication technologies to support patients with COPD in their self-management efforts across the illness trajectory, not just in relation to maintaining functional gains immediately post-PR. Cell phones will only continue to evolve and are expected to be robust ubiquitous computing devices in the future. Second generation devices already integrate motion and physiological sensors, location-based tracking, persuasive audiovisual media, and applications that support the formation of organic social networks; these tools will no doubt transform and perhaps, enhance the construction of more effective and personalized behavioral interventions for health promotion and disease management in the near future. However, the primary methodological challenge for future research on any technology-mediated clinical or behavioral intervention is the rapid changes in the technologies themselves which could undermine both internal and external study validity. 


\section{Author contributions}

Nguyen, Steele, and Benditt contributed to the concept and design of the study. Nguyen, Gill, and Wolpin acquired data and performed analysis and interpretation of data. Nguyen, Gill, Wolpin, Steele, and Benditt drafted the article and revised it critically for important intellectual content. Final approval of the version to be submitted was given by Nguyen, Gill, Wolpin, Steele, and Benditt. No author has any financial or personal relationships with other people or organizations that could inappropriately bias this work. The study sponsor played no role in the study design, data collection, analysis and interpretation of data, and writing of the manuscript. This study was supported in part by: R03 NR009361 and 1KL2RR025015-01; Omron Healthcare donated the pedometers.

\section{References}

1. Ries AL, Bauldoff GS, Carlin BW, et al. Pulmonary Rehabilitation: Joint ACCP/AACVPR Evidence-Based Clinical Practice Guidelines. Chest. 2007;131(5 Suppl):4S-42S.

2. Brooks D, Krip B, Mangovski-Alzamora S, Goldstein RS. The effect of postrehabilitation programmes among individuals with chronic obstructive pulmonary disease. Eur Respir J. 2002;20(1):20-29.

3. Donesky-Cuenco D, Janson S, Neuhaus J, Neilands TB, CarrieriKohlman V. Adherence to a home-walking prescription in patients with chronic obstructive pulmonary disease. Heart Lung. 2007;36(5):348-363.

4. Heppner PS, Morgan C, Kaplan RM, Ries AL. Regular walking and long-term maintenance of outcomes after pulmonary rehabilitation. J Cardiopulm Rehabil. 2006;26(1):44-53.

5. Rodriguez-Roisin R. Global Initiative for Chronic Obstructive Lung Disease (GOLD) writing group. Global strategy for the diagnosis, management, and prevention of chronic obstructive pulmonary disease. 2008. Accessed July 30, 2009. Available from http://www. goldcopd.com/.

6. Troosters T, Gosselink R, Decramer M. Short- and long-term effects of outpatient rehabilitation in patients with chronic obstructive pulmonary disease: a randomized trial. Am J Med. 2000;109(3):207-212.

7. Foglio K, Bianchi L, Ambrosino N. Is it really useful to repeat outpatient pulmonary rehabilitation programs in patients with chronic airway obstruction? A 2-year controlled study. Chest. 2001;119(6):1696-1704.

8. Ries AL, Kaplan RM, Myers R, Prewitt LM. Maintenance after pulmonary rehabilitation in chronic lung disease: A randomized trial. Am J Respir Crit Care Med. 2003;167(6):880-888.

9. Grosbois JM, Lamblin C, Lemaire B, et al. Long-term benefits of exercise maintenance after outpatient rehabilitation program in patients with chronic obstructive pulmonary disease. J Cardiopulm Rehabil. 1999;19(4):216-225.

10. Steele BG, Belza B, Cain KC, et al. A randomized clinical trial of an activity and exercise adherence intervention in chronic pulmonary disease. Arch Phys Med Rehabil. 2008;89(3):404-412.

11. Garcia-Aymerich J, Lange P, Benet M, Schnohr P, Antó JM. Regular physical activity reduces hospital admission and mortality in chronic obstructive pulmonary disease: a population based cohort study. Thorax. 2006;61(9):772-778.

12. Harris Interactive. Cell Phone Usage Continues to Increase. April 4, 2008. Available from: http://www.harrisinteractive.com/harris_poll/ index.asp?PID=890. Accessed April 26, 2009.

13. Patrick K, Griswold WG, Raab F, Intille SS. Health and the mobile phone. Am J Prev Med. 2008;35(2):177-181.
14. Hurling R, Catt M, Boni MD, et al. Using internet and mobile phone technology to deliver an automated physical activity program: randomized controlled trial. J Med Internet Res. 2007;9(2):e7.

15. Patrick K, Raab F, Adams MA, et al. A text message-based intervention for weight loss: randomized controlled trial. J Med Internet Res. 2009;11(1):e1.

16. Brendryen H, Drozd F, Kraft P. A digital smoking cessation program delivered through internet and cell phone without nicotine replacement (happy ending): randomized controlled trial. J Med Internet Res. 2008;10(5):e51.

17. King AC, Ahn DK, Oliveira BM, Atienza AA, Castro CM, Gardner CD. Promoting physical activity through hand-held computer technology. Am J Prev Med. 2008;34(2):138-142.

18. Kim HS, Song MS. Technological intervention for obese patients with type 2 diabetes. Appl Nurs Res. 2008;21(2):84-89.

19. Logan AG, McIsaac WJ, Tisler A, et al. Mobile phone-based remote patient monitoring system for management of hypertension in diabetic patients. Am J Hypertens. 2007;20(9):942-948.

20. Krishna S, Boren SA, Balas EA. Healthcare via cell phones: a systematic review. Telemed J E Health. 2009;15(3):231-240.

21. Liu WT, Wang CH, Lin HC, et al. Efficacy of a cell phone-based exercise programme for COPD. Eur Respir J. 2008;32(3):651-659.

22. Nguyen HQ, Donesky-Cuenco D, Wolpin S, et al. A randomized trial of an Internet-based versus a face-to-face dyspnea self-management program for patients with chronic obstructive pulmonary disease: A pilot study. J Med Internet Res. 2008;10(2):e9.

23. Kraemer HC, Mintz J, Noda A, Tinklenberg J, Yesavage JA. Caution regarding the use of pilot studies to guide power calculations for study proposals. Arch Gen Psychiatry. 2006;63(5):484-489.

24. Bravata DM, Smith-Spangler C, Sundaram V, et al. Using pedometers to increase physical activity and improve health: a systematic review. JAMA. 2007;298(19):2296-2304.

25. Bandura A. Social foundations of thought and action. A social cognitive theory. Englewood Cliffs, NJ: Prentice Hall; 1986.

26. Bandura A. Self-efficacy: the exercise of control. New York, NY: W.H. Freeman; 1997.

27. Rothman AJ, Baldwin AS, Hertel AW. Self-regulation and behavior change: Disentagling behavioral initaition and behavioral maintenance. In: Vohs K, Baumeister L, editors. Handbook of Self-Regulation. New York, NY: Guildford Press; 2004.

28. Ryan RM, Connell JP. Perceived locus of causality and internalization: examining reasons for acting in two domains. J Pers Soc Psychol. 1989;57(5):749-761.

29. Levesque CS, Williams GC, Elliot D, Pickering MA, Bodenhamer B, Finley PJ. Validating the theoretical structure of the Treatment SelfRegulation Questionnaire (TSRQ) across three different health behaviors. Health Educ Res. 2007;22(5):691-702.

30. Hibbard JH, Mahoney ER, Stockard J, Tusler M. Development and testing of a short form of the patient activation measure. Health Serv Res. 2005;40(6 Pt 1):1918-1930.

31. Hibbard JH, Stockard J, Mahoney ER, Tusler M. Development of the Patient Activation Measure (PAM): conceptualizing and measuring activation in patients and consumers. Health Serv Res. 2004;39(4 Pt 1):1005-1026.

32. Larson J, Covey M, Kapella M. Barriers to efficacy: COPD version [abstract]. Am J Respir Crit Care Med. 2003;167:A673.

33. Duncan TE, Duncan SC, McAuley E. The role of domain and gender-specific provisions of social relations in adherence to a prescribed exercise regimen. J Sport Exerc Psychol. 1993;15(2):220-231.

34. Sallis JF, Grossman RM, Pinski RB, Patterson TL, Nader PR. The development of scales to measure social support for diet and exercise behaviors. Prev Med. 1987;16:825-836.

35. Litt MD, Kleppinger A, Judge JO. Initiation and maintenance of exercise behavior in older women: predictors from the social learning model. J Behav Med. 2002;25(1):83-97.

36. ATS Committee on Proficiency Standards for Clinical Pulmonary Function Laboratories. ATS statement: guidelines for the six-minute walk test. Am J Respir Crit Care Med. 2002;166:111-117. 
37. Fishman A, Martinez F, Naunheim K, et al. National Emphysema Treatment Trial Research Group. A randomized trial comparing lung-volume-reduction surgery with medical therapy for severe emphysema. N Engl J Med. 2003;348(21):2059-2073.

38. Normandin EA, McCusker C, Connors M, Vale F, Gerardi D, ZuWallack RL. An evaluation of two approaches to exercise conditioning in pulmonary rehabilitation. Chest. 2002;121(4): 1085-1091.

39. Stulbarg MS, Carrieri-Kohlman V, Demir-Deviren S, et al. Exercise training improves outcomes of a dyspnea self-management program. J Cardiopulm Rehabil. 2002;22(2):109-121.

40. Cavanaugh JT, Coleman KL, Gaines JM, Laing L, Morey MC. Using step activity monitoring to characterize ambulatory activity in community-dwelling older adults. J Am Geriatr Soc. 2007;55(1):120-124.

41. Gardner AW, Montgomery PS, Scott KJ, Afaq A, Blevins SM. Patterns of ambulatory activity in subjects with and without intermittent claudication. J Vasc Surg. 2007;46(6):1208-1214.

42. Ware JE Jr, Sherbourne CD. The MOS 36-item short-form health survey (SF-36). I. Conceptual framework and item selection. Med Care. 1992;30(6):473-483.

43. Jones PW, Quirk FH, Baveystock CM, Littlejohns P. A self-complete measure of health status for chronic airflow limitation. The St. George's Respiratory Questionnaire. Am Rev Respir Dis. 1992;145(6):1321-1327.

44. Jones PW, Quirk FH, Baveystock CM. The St George's Respiratory Questionnaire. Respir Med. 1991;85(Supp1 B):25-31; discussion 33-37.
45. de Blok BM, de Greef MH, ten Hacken NH, Sprenger SR, Postema K Wempe JB. The effects of a lifestyle physical activity counseling program with feedback of a pedometer during pulmonary rehabilitation in patients with COPD: a pilot study. Patient Educ Couns. 2006;61(1):48-55.

46. Clemes SA, Parker RA. Increasing our understanding of reactivity to pedometers in adults. Med Sci Sports Exerc. 2009;41(3):674-680.

47. Watz H, Waschki B, Boehme C, Claussen M, Meyer T, Magnussen H. Extrapulmonary effects of chronic obstructive pulmonary disease on physical activity: a cross-sectional study. Am J Respir Crit Care Med. 2008;177(7):743-751.

48. Watz H, Waschki B, Meyer T, Magnussen H. Physical activity in patients with COPD. Eur Respir J. 2009;33(2):262-272.

49. Hospes G, Bossenbroek L, Ten Hacken NH, van Hengel P, de Greef MH. Enhancement of daily physical activity increases physical fitness of outclinic COPD patients: results of an exercise counseling program. Patient Educ Couns. 2009;75(2):274-278.

50. Pitta F, Troosters T, Probst VS, Langer D, Decramer M, Gosselink R. Are patients with COPD more active after pulmonary rehabilitation? Chest. 2008;134(2):273-280.

51. King AC, Friedman R, Marcus B, et al. Ongoing physical activity advice by humans versus computers: the Community Health Advice by Telephone (CHAT) trial. Health Psychol. 2007;26(6):718-727.
International Journal of COPD

\section{Publish your work in this journal}

The International Journal of COPD is an international, peer-reviewed journal of therapeutics and pharmacology focusing on concise rapid reporting of clinical studies and reviews in COPD. Special focus is given to the pathophysiological processes underlying the disease, intervention programs, patient focused education, and self management protocols.

\section{Dovepress}

This journal is indexed on PubMed Central, MedLine and CAS. The manuscript management system is completely online and includes a very quick and fair peer-review system, which is all easy to use. Visit http://www.dovepress.com/testimonials.php to read real quotes from published authors. 